\title{
La cirugía invisible: el caso de los hueseros Escobar de Cliza (Cochabamba, Bolivia)
}

\author{
Pedro Pablo Salvador Hernández \\ Universidad de Castilla-La Mancha \\ ppsh@telefonica.net
}

Recibido: 18 de junio de 2010

Aceptado: 24 de noviembre de 2010

RESUMEN

Este artículo trata de ahondar en el uso de prácticas simbólicas concretas extraídas de la experiencia etnográfica que pueden contribuir a arrojar luz, desde una perspectiva socio-antropológica, sobre el fenómeno del éxito terapéutico de la saga de hueseros de Cliza en Cochabamba, Bolivia.

Palabras clave: Hueseros, medicina popular, etnomedicina, eficacia simbólica, Bolivia.

\section{Invisible Surgery: The Case of the Escobars, Bonesetters from Cliza (Cochabamba, Bolivia)}

\begin{abstract}
This paper tries to delve into the use of specific symbolic practices drawn from the ethnographic experience that can help to shed light, from a socio-anthropological perspective, to the phenomenon of therapeutic success of the saga of bonesetters from Cliza, in Cochabamba, Bolivia.
\end{abstract}

Key words: Bonesetters, folk medicine, ethno-medicine, symbolic efficacy, Bolivia.

SUMARIO: 1. La tradición de los hueseros Escobar: cinco generaciones de frotadores. 2. El emplasto de yema de huevo y la «maniobra Escobar». 3. La cirugía invisible. 4. La magia del hombre medicina. 5. Conclusiones. 6. Referencias bibliográficas.

La enfermedad es más vieja que el hombre.

Erwin H. Ackerknecht

\section{La tradición de los hueseros Escobar: cinco generaciones de frotadores}

El municipio de Cliza se encuentra a una distancia de 37 kilómetros de Cochabamba (unos cuarenta minutos por carretera), en un área geográfica denominada el Valle Alto. Cliza (pronunciado «Clisa») es una pequeña localidad situada a unos 2.750 m.s.n.m. que destaca, según proclama la tradición, por su gastronomía local, con la especialidad del pichón y las ferias artesanales agropecuarias. Sin embargo, la principal atracción para visitantes la ofrece la tradición sanadora de las tres clínicas de hueseros, de los hermanos Aldo, Ramiro y Orlando Escobar Cano, que reciben a una cantidad notable de pacientes que oscila entre sesenta y setenta diarios, con especial concentración los domingos, cuando se puede duplicar la cifra. Su popularidad se extiende por todo el Departamento de Cochabamba y tiene ecos a lo largo de toda la geografía boliviana.

«La tradición de los Escobar empieza por la necesidad. No había muchos médicos antes en la zona. Entonces, uno de mis abuelos empieza con todo esto. La gente lo buscaba a él porque era muy conocido. Y fue con la práctica que él empezó a hacer todo esto, ¿no? [...] Tenía conocimientos básicos que fue puliendo a medida que pasaban los años. Y ahí 
fue donde empezó, digamos, a practicar más en serio lo que antes se llamaba homeopatía, después osteopatía y luego empezó a tener un montón de nombres. Lo conocían a él como el Jhaqhodor que en quechua era (en el idioma nativo) el frotador. [...] Y ahora, más nos conocen por hueseros [...] todo el mundo nos conoce de hueseros. [...] (Tratamos) todo lo relacionado con el sistema óseo. (Mi tatarabuelo) siempre, siempre se ha dedicado más a los huesos, ligamentos, tendones. Todo, todo lo que era esa parte ¿no? Digamos que otro tipo de males, no. No los atendía. Por eso, de ahí, le llamaban el huesero, porque hacía más eso.

[...] El conocimiento se ha transmitido de generación en generación, ¿no? Los padres enseñaban a los hijos. Bueno, lo que pasa en nuestra familia es que siempre quedaba solamente un hijo. Pura mujeres, un hijo. Entonces, el hijo era el que aprendía y él se lo pasaba a su hijo. Ya en esta última generación que era de mi abuelo, él pasó a tres hijos y esos tres hijos son los que actualmente están atendiendo, ¿no? Es lo único, puro hijo, hijo, hijo. Nada más, uno solo. Pero fue pasando así de generación en generación» (Farith Escobar, Cliza, Cochabamba, 2009).

Transcribo un fragmento biográfico de la familia Escobar, narrado por Aldo Escobar, de la única referencia bibliográfica publicada que he podido encontrar en Bolivia (aparte de información en diarios locales) tras un meticuloso proceso de indagación, ya descrito en otro artículo previo (Salvador 2010).

«En este marco, nuestro trabajo, está exclusivamente relacionado con la curación y tratamiento de huesos, vale decir en otras palabras que realizamos curaciones desde una simple luxadura, hasta fracturas y otro tipo de alteraciones o desubicaciones, la recomposición de la estructura ósea malograda y dislocaciones. A esta labor estamos dedicados los tres hermanos [...] al mismo tiempo practicamos lógicamente orientados y asesorados por nuestro venerado y recordado padre Don Luis Escobar Terceros, el mismo que a su vez recibió las peculiares enseñanzas de sus padres y abuelos, profesión que ejercemos en los hechos y la práctica por tradición, ya que esta forma de curación se remonta a los tiempos del siglo pasado de nuestro BISABUELO cuyo nombre era MANUEL ESCOBAR, el mismo que, viendo la impotencia, la angustia y el sufrimiento de nuestra gente sin recursos económicos suficientes como para acudir a los servicios profesionales en un Centro Hospitalario, fue lo que en realidad le indujera a un consciente y concienzudo estudio de la conformación ósea del cuerpo humano, y ante este cuadro desesperante y sin esperanza alguna es que el citado bisabuelo recurrió a la naturaleza para curar las lesiones y fracturas sin mas auxilio y ayuda que la habilidad y agilidad de sus manos experimentadas en este tipo de trabajo» (Guillén 1995: 4-5).

La narración coincide con lo expresado en varias entrevistas por los hermanos Escobar, así como con la historia que recoge la costumbre oral popular que explica cómo Manuel Escobar, aquejado de una fractura de hueso y sin recursos para utilizar la medicina convencional, tuvo que «autocurarse» recurriendo a los remedios que sus ancestros le habían transmitido: colocación del hueso, inmovilización y emplasto de tabaco y huevo. Su sanación fue tan eficaz y rápida que pronto se corrió la voz entre sus allegados, iniciándose la saga de los Escobar con una tendencia creciente en la atención a pacientes hasta la actualidad.

«Vienen de Argentina, viene de Brasil, de Chile he tenido, de Perú he tenido, incluso han venido de Checoslovaquia. Justamente, por la entrevista que me hicieron se vino gente de Checoslovaquia por las famosas lumbalgias, que ya nada podían hacer, pues 


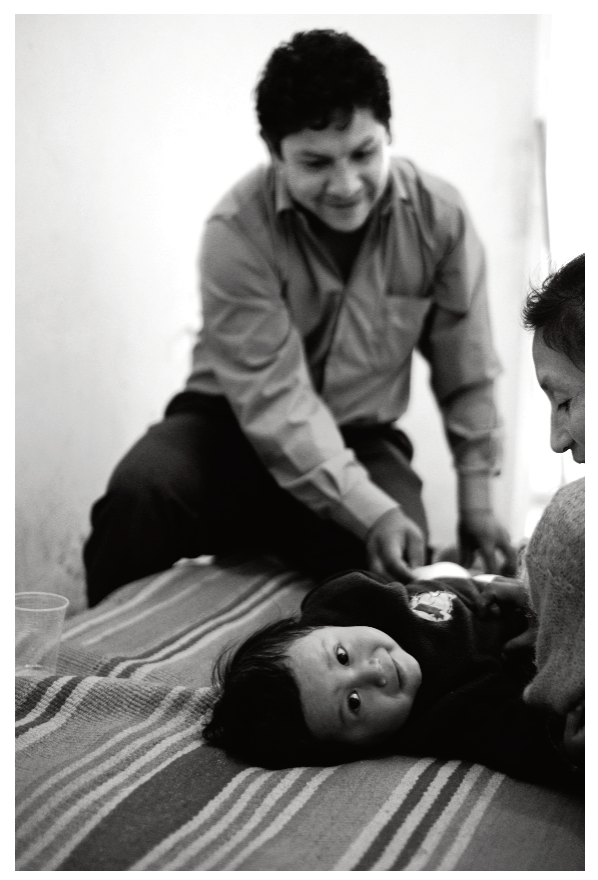

vinieron aquí y se quedaron un mes y se fueron contentos» (Farith Escobar, Cliza, Cochabamba, 2008).

La familia Escobar cuenta con un gran reconocimiento social, no sólo entre la población civil, sino también entre especialistas en medicina tradicional, que no dudan en alabar su trabajo, o incluso citarlos como su propia fuente de aprendizaje. Es más, su prestigio como hueseros es tal que curanderos y naturistas aluden a ellos para reforzar su propio estatus en materia médica. Mostrar cualquier vínculo con ellos (amistad, coincidencia en congresos o seminarios, haber aprendido de ellos, utilizarlos como supervisores de tratamientos, etc.) es una constante entre la corte de sanadores de Cochabamba.

Así narra el naturista Jorge Rico un encuentro con Aldo Escobar para abordar la fase final de la curación de un Senador por Pando que padeció una fractura de hombro:

«Conozco a los hueseros Escobar, los de Cliza, a dos no más, a don Aldo el más alto y después el siguiente el Orlando [...] si él, a él le conozco pero, al Ramiro no lo conozco. Trabajan bien [...] Doy un ejemplo de don Aldo: Un senador por Pando, es un departamento en el norte, [...] estaba en La Paz, pero [...] su mujer vivía en Cochabamba y era mi paciente. [...] El senador estaba en La Paz porque había que asistir a las reuniones del senado y, estando subiendo las gradas, de repente le ha venido un mareo, porque La Paz es alto, y entonces, se ha ido hacia atrás y en vez de caer de cabeza ha caído de aquí (con el hombro) y esto se ha deshecho. Le han llevado a una clínica privada en ese mismo momento [...] y le han hecho una operación [...] Han pasado mientras tanto veintidós días y la señora me telefonea (ahora desde La Paz) y me dice: «señor Rico,[... 
] quiero llevarle a mi marido, ha sucedido esto» [...] Le dije: «mire tráigalo esta misma noche en el avión de las ocho de la noche» [...] Y a ese señor le hecho el primer tratamiento, segundo tratamiento [...] Le he dado una pelotita de tenis para darse masajes [...] y el senador dice: "cómo me va a dar usted esas cositas para jugar, iyo no soy niño!. Le digo ¡hágalo i [...] No ha podido hacer al principio ha tenido que aprender de cero a sentir y después a agarrar esto con los dedos [...] ya está trabajando los nervios, los músculos, los huesos [...] En veintidós días, hemos ido donde Aldo Escobar él ha dicho «¿y qué hay que hacer con usted?» - Él estaba mirando las caquitas de gallina, después bajaba al conejo, al gato, al pato. «¿A dónde me ha traído usted?», me dice el senador, «a mí no me mira ese». Le digo: «mire la capacidad que tiene el doctor es increíble» [...] Ha aceptado y lo ha mejorado. «Esto - ha dicho Aldo - es cuestión de un movimiento. Todo está preparado, ha hecho usted bien señor Rico». Bueno le ha hecho sentar correctamente y aquí lo ha agarrado (mientras lo hablaba ya lo preparó el material tabaco con otras cosas más) y en un segundo le ha colocado el hombro». El senador salió de casa de Aldo sorprendido ¿no?, moviendo el brazo como si nunca se hubiera malogrado y satisfecho de haber ido a Cliza» (Jorge Rico, Cochabamba, 2009).

Es interesante el fragmento en la medida en que el Naturista Jorge Rico pone en valor a Aldo Escobar en una curación de un relevante personaje público (de quien prudentemente no cita el nombre), y cómo a través del discurso implícitamente se auto-prestigia: «Todo está preparado, ha hecho usted bien señor Rico». Del mismo modo, es curioso cómo en este caso, la medicina tradicional (caracterizada en lo rural mediante gallinas, gatos, conejos y patos) tiene que socorrer a la cirugía, que a pesar de haber intervenido al Senador no había sido capaz de curarlo.

El ingeniero y médico tradicional Juan Coca, que ha sido Presidente de SO.BO.ME.TRA, la Sociedad Boliviana de Medicina Tradicional ${ }^{1}$ me informa acerca de un conocimiento anclado en los hueseros Escobar del Doctor José Demetrio Villegas, uno de los más reputados especialistas en el tratamiento del dolor de espalda de Cochabamba ${ }^{2}$.

«José Demetrio Villegas [...] es médico, tiene una especialidad creo en Brasil, pero ha estudiado a los hueseros que son de Cliza, a los Escobar. Y en una palabra se puede decir que él les ha sacado toda su sabiduría a los hijos, porque el padre ya dejó de existir tiempo atrás. Él era médico, y los Escobar, pues lo han informado todo, y empezó a especializarse en huesos y recién, en algo tan complejo como la osteoporosis» (Juan Coca, Cochabamba, 2009).

La familia Escobar dispone de un reconocimiento social y un éxito profesional sin precedentes en el departamento de Cochabamba, en un contexto de convivencia de la medicina convencional con la medicina tradicional. En cuestión de afecciones óseas, las posiciones hegemónicas y subalternas se invierten para una parte de la sociedad civil. Como explica Perdiguero (2006), es casi generalizado que los grupos humanos recurran a diferentes «instancias asistenciales y terapéuticas» para abordar sus pro-

${ }^{1}$ SO.BO.ME.TRA: Sociedad Boliviana de Medicina Tradicional que aúna a numerosos especialistas en medicina tradicional, kallawayas, hueseros, curanderos, etc. Registrada en 1984, es la primera institución del país que ha agrupado formalmente a médicos tradicionales en Bolivia

2 José Demetrio Villegas dirige el Centro Médico del Dolor de Espalda (CEMDE). Para más información consultar la página web del centro: http://www.herniadedisco.com.bo/ 
blemas de salud. Lógicamente, la dimensión sociocultural de la enfermedad ha consolidado una tradición en los hueseros que transciende a la población rural. Su éxito actual como sanadores procede de su experiencia EN la hibridación de sistemas médicos (biomedicina ${ }^{3}$ y medicina tradicional) y en la honestidad profesional a la hora de derivar a sus pacientes ante la incapacidad de atender un caso.

«Cuando ya definitivamente el caso no es para tratarlo naturalmente, se los ha remitido (al hospital). Por ejemplo, fractura con exposición, que son los que causan las infecciones [...] Sí, obviamente, nos ayudamos bastante en medicina científica [...] Obviamente, hay casos ya muy, muy graves que definitivamente se tiene que abrir y hacerlo quirúrgicamente.» (Aldo Escobar, Cliza, Cochabamba, 2009).

No es de extrañar que este contexto, en combinación con las ideas médicas de los indígenas, el cuerpo de medicina popular generado por los frotadores de Cliza desempeñe un papel funcional en los ciudadanos locales que resistirán a la penetraciones de la biomedicina como ciencia hegemónica durante muchas generaciones (Foster 1980).

\section{El emplasto de yema de huevo y la «maniobra Escobar»}

Considero que dos de los elementos que más han consolidado a la familia Escobar entre el público general y los especialistas médicos (aparte de su conocimiento enciclopédico del tratamiento de afecciones del aparato locomotor del cuerpo humano) son la aplicación del emplasto de yema de huevo y quinua para acelerar el proceso de soldado de las fisuras y fracturas, y la eficacia de la que me atrevo a denominar «maniobra Escobar» para curar o aliviar la lumbalgia. Paso a describir estas dos señas de identidad de los frotadores Escobar.

\subsection{El emplasto de yema de huevo y tabaco}

Un emplasto es un preparado para aplicar directamente sobre la piel, con cierta solidez, moldeable y que se adhiere a la zona afectada. Farith Escobar (hijo de Aldo Escobar), quien defiende ser médico titulado y huesero tradicional, me explica que la bondad de aplicar el huevo con el tabaco es el poder precipitador del calcio en las fracturas y fisuras, consiguiendo reducciones de tiempo en la sanación de huesos que oscilan entre un treinta y un cuarenta por ciento, según sus estimaciones. Afirma que en algunas patologías la curación se produce en la mitad de tiempo con los emplastos renovados cada semana o cada quince días si lo comparamos con los resultados obtenidos con la medicina convencional. Todos los pacientes con los que conversé, sin excepción, estaban convencidos de que los tiempos de curación de sus fracturas, comparados con el tratamiento de yeso o escayola, se reducían significativamente. Los

\footnotetext{
${ }^{3}$ «la biomedicina misma (puede ser considerada) como uno más de los sistemas médicos que se han constituido en el mundo. Sistema, ciertamente diferente, por basarse en el método científico (con todos los presupuestos y las implicaciones que esto comporta), pero al mismo tiempo, al igual que los otros sistemas, institución social y estructura de poder, y como otros, en cada caso, aparato ideológico-cultural y organizativo históricamente determinado» (Seppilli 2000: 37).
} 
hueseros utilizan cartón y una venda en lugar de yeso. Por ejemplo, un futbolista profesional del equipo Aurora de Cochabamba, al que pude entrevistar durante una visita de control y seguimiento de la evolución de una fisura en la tibia, me explicaba que en su experiencia ganaba más de quince días para incorporarse al equipo con los cuidados de los hueseros, respecto a los médicos de los centros de salud.

Una de las razones para explicar este fenómeno, puede tener que ver con la osmolaridad ${ }^{4}$. Es decir, la piel (el uso tópico de cremas, ungüentos, aceites, tinturas, pomadas, gelatinas, cataplasmas, fomentos, etc.) es una de las vías de acceso de una sustancia al interior del organismo y en la medicina indígena conserva una vigencia absoluta en el territorio de Cochabamba. El doctor Luis Villegas lo resume en los siguientes términos con su argot biomédico:

«Entonces, otra conclusión: cataplasmas, fomentos. Todo lo que se aplica desde afuera, ¿por qué hace efecto? El hueso o tejidos osteoarticulares de poca irrigación hacen su intercambio nutricional metabólico a través de la bomba iónica ${ }^{5}$. Es la osmolaridad que utiliza. Por más remedio que tome, eso no le llega al hueso, pero sí lo activo desde afuera inclusive por acto, la osmolaridad. Es excelente una cataplasma. Acabo de indicar al paciente que se ha ido - usted se va poner los fomentos toda la noche» (Luis Villegas, Cochabamba, 2009).

La receta consiste en aplicar sobre la piel, mediante un emplasto untado sobre papel madera, un preparado que la familia mantiene en secreto. Sin embargo, entrevistando a otros especialistas en medicina tradicional, consultando bibliografía y con un poco de análisis comparativo, es sencillo llegar a los ingredientes de la misma. Una buena síntesis la ofrece el naturista Juan Coca de Cochabamba:

«Los hermanos Escobar utilizan tabaco criollo, yema de huevo y [...] quinua amarga. Es otra especie [...] la quinua amarga es más amarga y la quinua real es la que comemos. Y la verdad funciona» (Juan Coca, Cochabamba, 2009).

El propio Aldo Escobar declara en una entrevista publicada en el contexto de un seminario de medicina tradicional en la Universidad Mayor de San Simon:

«Los cataplasmas se elaboran en base a yema de huevo criollo, tabaco y un poco azúcar. Este cataplasma es recomendable utilizar en caso de rajadura o fisura de hueso, también se utiliza en caso de presentarse fractura de fémur, tibia, peroné. etc.» (Borda 1953: 59).

La utilización de esta mezcla se ha popularizado entre los curanderos locales por su eficacia curativa y es parte del recetario público de los hueseros de esta región boliviana. Rigoberto Paredes señala que el trabajo de los curanderos indígenas en materia

\footnotetext{
${ }^{4}$ La osmolaridad es la medida usada por farmacéuticos y médicos para expresar la concentración total (medida en osmoles/litro en vez de en moles/LITRO como se hace en química) de sustancias en disoluciones usadas en medicina. El prefijo «osmo-» indica la posible variación de la presión osmótica en las células, que se producirá al introducir la disolución en el organismo. La ósmosis es un fenómeno físico-químico relacionado con el comportamiento del agua -como solvente de una solución- ante una membrana semipermeable para el solvente (agua) pero no para los solutos. Tal comportamiento entraña una difusión simple a través de la membrana, sin «gasto de energía». La ósmosis es un fenómeno biológico importante para la fisiología celular de los seres vivos.

${ }^{5}$ Bomba iónica: Mecanismo de transporte iónico activo, que consume energía a través de una membrana en contra de un gradiente electromecánico. Mantiene las diferencias características en la concentración iónica entre el espacio intracelular y el extracelular.
} 
anatómica está corroborado desde la antigüedad, aportando en su análisis de la medicina tradicional boliviana abundante documentación histórica para al final añadir:

«Semejantes curaciones no son extrañas al presente entre los indios. Como no existen en las poblaciones rurales ni médicos, ni boticas, son los curanderos indígenas los que hacen que las reducciones, en los casos de luxaciones y fracturas, con singular maestría y después ponen emplastos de yerbas en las partes enfermas hasta que sane el enfermo» (Paredes 1963: 245).

La particularidad del uso del emplasto sigue la siguiente secuencia temporal:

1. El paciente es revisado generalmente mediante la observación y el tacto del huesero, y diagnosticado de su patología. Esta operación no requiere más de veinte segundos. Los dedos de Farith o Aldo Escobar están acostumbrados a visualizar el sistema osteo-articular a través de sus manos como si la piel fuera papel escrito con braille para un invidente formado en este sistema de lectura.

2. El hueso (o la articulación) del usuario de los servicios es colocado en apenas diez segundos, sin calentamiento de la zona, acompañado casi siempre de un chasquido seco y un gesto (o en ocasiones de un aullido) de dolor del afectado.

3. El huesero coloca el emplasto de tabaco y huevo en la zona afectada, justo unos instantes después de batirlo manualmente sobre papel madera.

4. Se envuelve la zona recién intervenida con una parte de la venda, la mitad aproximadamente. Sobre ella, se acopla una férula de cartón que el huesero ha doblado con sus manos hasta darle la forma precisa del lugar en el que se va a aplicar. Se continúa el vendaje hasta cubrir por completo la férula y se fija la venda con una pieza metálica o un trozo de esparadrapo. El motivo del uso del cartón, en palabras de los hueseros, es con el objeto de poder adaptar la forma al tamaño requerido y, además, por ser un material más flexible y menos prejudicial para la piel que el yeso.

5. El huesero grita -«el que sigue»-y acompaña a la persona curada a la sala de espera donde públicamente dice a su asistente el precio de la consulta y de la venda, faja o parchecito, que se cobran a parte.

Quizás, merezca la pena señalar que durante varias de mis observaciones en la clínica de los hueseros, algunos pacientes, excepcionalmente, se han visto afectados de enrojecimientos, picores, irritaciones, sarpullidos, eccemas u otras reacciones en la piel asociadas al uso del tabaco con huevo. En estos casos, Farid ha recetado algún tipo de pomada para la dermatitis y ha suspendido el tratamiento:

«Si tengo, por ejemplo, una complicación como esto de la dermatitis, utilizo algún fármaco que me va a curar en un día. Y eso es lo que hago, una vez terminado el problema sigo con el tratamiento tradicional» (Farith Escobar, Cliza, Cochabamba, 2009).

Por ejemplo, ésta es la breve transcripción de la actuación de Aldo ante un jovencito que padeció una irritación de la piel por la continuidad en el tratamiento con tabaco. Considero destacable el cuidado que los hueseros ponen siempre en sus pacientes y el constante seguimiento de sus tratamientos hasta la curación final:

«Tenía fractura, se hizo cambiar (el emplasto) varias veces, [...] lo haremos descansar un poquito la piel, ¡tanto parche le he puesto! [...] No vamos a poner (más) por el momento está muy delicado la piel, tanto parche, tanto absorber, no conviene. También, que descanse un poquito hasta el domingo. Luego uno más vamos a poner, no aguanta 
pues la piel como es wawa [bebé] todavía, ahora sí puedes alegrarte hijito, todas las veces que venía lloraba pues,... se perjudica [...] Está medio hundido pero se curará» (Aldo Escobar, Cliza, Cochabamba, 2009).

\subsection{La maniobra Escobar}

Las patologías relacionadas con el dolor de espalda son las que más pacientes atraen a los hueseros Escobar. En concreto la lumbalgia, o dolor de espalda en la zona lumbar, representa más del cincuenta por ciento de las patologías atendidas a diario. Es sorprendente contemplar la habilidad y velocidad con la que se aplica la «maniobra Escobar». La maniobra es una peculiar manipulación (también denominada «manipuleo óseo», Guillén 1995: 8), que consiste en un movimiento seco forzado sobre la columna que describiré pormenorizadamente a continuación. Algunos pacientes son despachados en menos de treinta segundos, tras un diagnóstico certero.

Los osteópatas de la región de Cochabamba conocen bien el término con el que se denomina al origen más frecuente de la lumbalgia: la subluxación sacro-ilíaca, una especie de imperceptible desplazamiento de una articulación o de una vértebra, en el caso lumbar, que presiona un haz nervioso para generar dolor y malestar en la persona afectada.

Uno de los argumentos más recurrentes por parte de médicos tradicionales es la incapacidad de detección de la medicina convencional de esta patología con el arsenal de instrumentos de diagnóstico más modernos como la tomografía o la resonancia magnética $y$, en consecuencia, la incapacidad para curar determinadas afecciones que la medicina tradicional aborda con éxito desde tiempos de la colonia. Veamos la explicación del Doctor Villegas para la subluxación desde su perspectiva híbrida entre biomedicina y medicina indígena:

«aparte de las traumáticas, que es una fractura o una luxación, que se ven y se pueden corregir, hay otras lesiones que producen hasta triple efecto: las subluxaciones que en términos médicos oficiales no se contemplan, pero tienen un efecto directo en la columna y todas las articulaciones. Genera presión sobre presión, aumenta la presión hasta 10 veces. Esa sobrepresión va a producir desgaste, por ejemplo en la rodilla. En la columna, va a hacer otros efectos colaterales. Porque también bloquea el haz vascularnervioso y el retorno linfático. De ahí que vienen las terapias, masajes, etc. (de los hueseros Escobar) [...] Para esto, la maniobra es fundamental:

La subluxación no se ve. A mí no me enseñaron en la facultad la existencia de esta patología. La luxación todo el mundo la ve, porque se ha salido fuera la articulación. Se recorrió un poco. La subluxación si apenas se desacomodó milimétricamente y no es detectable (con) radiografía, tomografía, resonancia magnética. Pero como no está en su lugar genera presión para trabajar, sigue trabajando, pero se va desgastando» (Luis Villegas, Cochabamba, 2009).

Por tanto, es sobre esta patología invisible o sobre este diagnóstico indígena sobre el que fundamentalmente se aplica al tratamiento de la lumbalgia. Paso a describir la secuencia temporal de atención a un paciente aquejado de lumbalgia:

1. El paciente manifiesta su dolor de espalda y el huesero le invita a tumbarse en la hamaca que se sitúa unos cuarenta centímetros del suelo. El o la paciente nunca ha de 
desnudarse, simplemente ha de aflojarse la ropa y dejar al descubierto la parte lumbar. Hay que destacar que el recato y el pudor de muchos hombres y mujeres hace que Aldo o Farith tengan institucionalizado que la parte de carne mostrada sea la menor posible. Este gesto de respeto sintoniza con las costumbres de las culturas quechua o aymara y con el marco ético y moral de los enfermos. Además, se correlaciona simbólicamente con las ideas indígenas de lo abierto y de lo cerrado. Como explica Fernández Juárez:

«La desnudez pretendida de los pacientes en las postas y hospitales produce un importante rechazo entre las mujeres aymaras. Los cuerpos abiertos muestran la intimidad de lo que debiera permanecer en el dominio privado, oculto a toda mirada indiscreta» (Fernández 1998: 273)».

2. El paciente es examinado en la zona lumbar mediante la visión y el tacto. Además, es posible que el huesero se apoye en la revisión de una radiografía o resonancia que ha traído el paciente, en su caso, o que él mismo realice una en la misma clínica para verificar el diagnóstico. No obstante, lo normal es que utilicen los signos que son una referencia visual y táctil para verificar la correcta o incorrecta disposición de las vértebras, así como para determinar el alcance de la lesión. Farid me explicó que la columna ha de estar recta y los abultamientos óseos a derecha e izquierda han de ser simétricos. Cualquier asimetría es un potencial síntoma de subluxación.

«Los signos son algo que nosotros podemos determinar. O sea, para las luxaciones de cadera, nosotros tenemos varios signos, los cuales nos indican qué está mal. Y ayudados con la clínica, - «me duele la espalda»- , pues ya sabemos qué es. [...] Son unas pequeñas variaciones (que detectamos) al tocar en la en parte sacra. Son tan pequeñas que a veces son imperceptibles, pero nosotros con experiencia, deduciremos. Solamente al tocar eso podemos saber si está mal o no» (Farith Escobar, Cliza, Cochabamba, 2008).

3. Aplicación de la maniobra. El paciente es colocado boca abajo con los brazos hacia detrás, pegados al cuerpo, sus piernas son estiradas y sujetas por un asistente. El huesero pide al afectado que se relaje y le balancea las caderas a izquierda y derecha y colocando las palmas de las manos a ambos lados de la columna en la zona lumbar. Rápidamente, ejecuta un movimiento seco hacia abajo que va asociado a un sonido de crujir de la vértebras, luego aplica cuatro o cinco nuevas presiones de forma ascendente a lo largo de la columna con una mano sobre la otra ya sobre las vértebras desde las lumbares a las cervicales.

4. El huesero coloca un parchecito y/o una venda en la zona lumbar, en función de la importancia de la lesión, cita a la semana siguiente o a los quince días al afectado y llama al siguiente paciente.

Normalmente el tratamiento de la lumbalgia dura entre tres semanas y un mes. La formalización de la cura es negociada entre paciente, huesero y comunidad social. Como en el complejo chamanístico (Lévi-Strauss 1987a), el chamán, el enfermo y el público participan en la cura con una especie de pacto social que tiene en cuenta 1) la voz del huesero que mediante el nuevo diagnóstico y revisión de los signos organiza las diversas etapas del proceso de sanación; 2) del paciente que determina la evolución de su estado de salud y percibe si nota o no una mejoría de la zona afectada; 3 ) del entorno social (familia, comunidad, etc.) que da fe de la recuperación de la salud del 


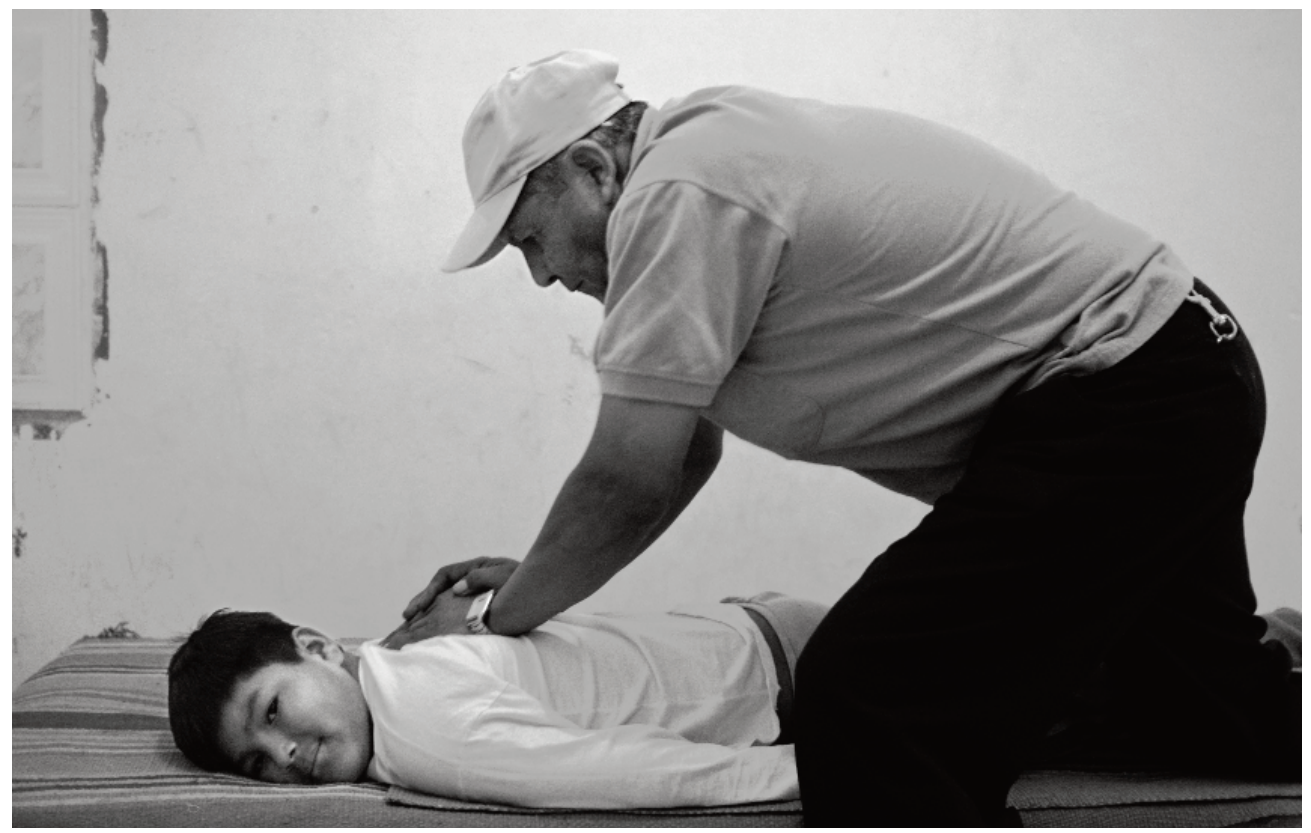

enfermo. Díaz Maderuelo (1983: 205) pone el dedo en la llaga al afirmar que en la cura, el contexto sociocultural es clave ya que «una enfermedad que no está definida culturalmente no se padece realmente». En el caso de los hueseros Escobar, su mera supervivencia en Cliza y su reconocimiento social creciente, no es más que fruto de los buenos resultados de sus tratamientos y de la sanción positiva de una comunidad moral que se siente escuchada, atendida y curada ya sea con sus emplastos de tabaco y huevo o con sus maniobras refinadas durante cinco generaciones.

\section{La cirugía invisible}

Existe un gran surtido de escenarios posibles en el camino que transcurre desde la toma de conciencia de la condición de persona enferma hasta llegar a la situación (o no) de persona sana. Es lo que se conoce en el perímetro de la antropología médica como «itinerario terapéutico» es decir, los pasos que se ponen en marcha para buscar una terapia (Perdiguero 2006: 41), que van desde la automedicación, a la petición de consejo al especialista ritual, pasando por la medicina convencional, el diagnóstico de los familiares, amigos o vecinos, la consulta telefónica, la telemedicina, la cibermedicina en la red, los grupos de autoayuda etc. Los itinerarios terapéuticos son intraculturales y tan diversos como los propios individuos y su rica condición de seres culturales.

Por supuesto, la cirugía es un eslabón más del itinerario terapéutico, pero ocupa una posición subalterna patente entre los pacientes de los hueseros Escobar, a los que acuden, precisamente, esquivando abrir el cuerpo. La cirugía es temida o desprestigiada como ineficaz por estos usuarios.

«Tres cirugías le han hecho, se fracturó el pié y la tibia. Después de la operación solo ha sido ingresada con fierro, le han sacado los clavos, pero está mal. Los calzados están 
chuecos, cuando hace frío le duele tanto. Mira cómo ha quedado de feo ese pie. No es normal, grueso ha quedado. Se le tuerce siempre el tobillo. La operación no ha servido nada. Mucha medicina, mucho calmante. [...] Se cayó del segundo piso al suelo, se rompió y tuvo tres astillas, se ha salido el hueso por el pantalón [...] Por eso, justamente después que le han operado le pusieron fierros, clavos y no sé que cosa salía por fuera también [...] Ella estaba con fierros de la importadora, esos fieros. [...] Todo un año ha estado así la pobre, como robot. Muy grande ha sido y muy cara la operación pero inútil, por eso venimos acá. Porque aquí sanan sin fierros, sin tener que abrir, sin medicamentos» (Madre de paciente en la clínica Escobar, Cliza, Cochabamba, 2008).

El cuerpo humano es concebido en esta área andina como un territorio físico y simbólico que ha de permanecer cerrado, hermético, no penetrado, con una similitud analógica con la piedra (Fernández 1998) que conforma una visión de fortaleza al relacionarse con cerros, peñas y montañas que son entidades protectoras y tutelares en esta fracción de la cosmología andina. Pero el tabú sobre las aperturas corporales quirúrgicas se ha extendido entre los pueblos amerindios de forma consistente, aunque ya estaban impregnados por las concepciones mentales de la Europa del siglo XVI y VII (Fernández 2009). Vemos cómo Ackerknecht explica la mala prensa de la cirugía respecto a otras formas de curación no invasivas:

«A partir de la baja Edad Media, la cirugía y los que la practicaban fueron considerados diferentes o inferiores a otros métodos o profesionales del arte de curar. Desde entonces, y durante 700 años, han estado separados del cuerpo de la medicina. En la sociedad moderna, la 'Cirugía' ha vuelto a formar parte de la medicina, pero como una de sus 'especialidades'» (Ackerknecht 1985: 97).

La cirugía se esquiva en el itinerario terapéutico híbrido y las terapias de los Escobar son un bálsamo frente a la percepción de agresividad de la intervención quirúrgica. Los hueseros, como especialistas terapéuticos desencadenan una zona de amortiguamiento (Ferrándiz 2004) frente a la posición de poder de la medicina científica, un lugar de reelaboración del sufrimiento humano. La práctica cotidiana del camino hacia la salud, lejos de la cirugía, bosqueja a estos actores sociales como piedras angulares de la comunicación intercultural entre posiciones antagónicas a la hora de de comprender el fenómeno de la salud y la enfermedad. Flores refleja la localización de estos mediadores con competencia cultural con la metáfora de la posición bisagra.

«Ello es debido al mantenimiento de posiciones híbrido o de «bisagra» entre al menos dos mundos y dos lógicas prácticas de enfrentar la aflicción y el mal que aquejan a sus convecinos o paisanos, con los que además de compartir su lengua, un imaginario y mundo cultural, comparten relaciones de confianza y de respeto» (Flores 2004: 200).

Sin embargo, Farith reflexiona con una gran sensatez al analizar el fenómeno de la cirugía. Su condición de especialista terapéutico híbrido (médico y huesero) y practicante de la cirugía invisible, relativiza el discurso crítico frente a la medicina convencional, exponiendo la necesidad de derivación en el itinerario terapéutico al marco de la medicina científica en caso necesario.

«La cirugía es muy buena, definitivamente, pero en los casos en que no se puede resolver naturalmente u ortopédicamente. Hay casos extremos donde, sí o sí, tienes que operarles, entonces no hay salvación. Pero los casos que sí se pueden resolver naturalmente 
aunque sean (diagnosticados como) quirúrgicos y se los puede resolver naturalmente, se tiene que hacer o por lo menos intentar, ya que lo que no es invasivo, siempre es mejor. La cirugía sería mi última opción. [...] Cuando ya definitivamente el caso no es para tratarlo naturalmente, sí se los ha remitido a cirujanos. Por ejemplo, fractura con exposición, que son los que causan las infecciones. [...] Nos ayudamos bastante en medicina científica ¿no?, con antibióticos. O sea, darle lo que corresponde para la herida. Entonces ha sanado. [...] Obviamente, hay casos ya muy, muy graves que definitivamente se tiene que abrir y hacerlo quirúrgicamente» (Farith Escobar, Cliza, Cochabamba, 2009).

La visión de respeto y complementariedad médica la considero de gran relevancia y es coincidente con la postura inversa, médicos convencionales cochabambinos que remiten a los hueseros a algunos de los pacientes. Esto me parece una idea fundamental: la pervivencia de los hueseros, no sólo se basa en su destreza para intervenir sin abrir, sino en la capacidad de enviar al paciente al marco de la biomedicina, si lo estima necesario, sin ningún tipo de duda. Esta actitud la he encontrado con mucha más frecuencia en el terreno de la medicina tradicional que en el de la medicina convencional. Una autora como Baer (Baer et al. 2006: 145), analizando la pervivencia de patologías populares, observa cómo los curanderos reconducen a sus pacientes a otros especialistas cuando se perciben como incapaces de dar una solución al enfermo: «A los que no sienten mejoría con un determinado tratamiento se les suele aconsejar que busquen a alguien con más poderes o a otro curandero».

La familia Escobar, al derivar al paciente, consigue por un lado poner al enfermo en el centro de la atención, dando respuesta a una demanda concreta frente a una patología que perciben que va más allá de sus competencias. Por otro, minimiza el riesgo de fracaso terapéutico, reforzando su posición de prestigio en el campo de la medicina popular. Y, finalmente, preservan su imagen de jhaghodores (frotadores) cuya actividad frente a los problemas óseos se desarrolla desde la superficie de la piel, sin vulnerar la concepción cosmológica de lo cerrado frente a lo abierto.

Es sensato pensar que todo sistema de aflicciones lleva aparejado un sistema terapéutico (Muñoz y López 2006). Ni un sistema puede abarcar todas las patologías posibles, ni hay sistemas de curación universales. Es la cultura local y el contexto sociocultural quien produce la concepción del fenómeno salud-enfermedad, así como las formas de sanar de un modo que se adecuen a su mapa de necesidades sanitarias a través de su propio modelo explicativo. Visto desde la sencillez y el ingenio analítico de Ackerknecht:

«La enfermedad es más vieja que el hombre. Es uno de los problemas vitales y básicos con los que se enfrenta cada sociedad, y toda sociedad humana conocida desarrolla métodos para tratar la enfermedad, y entonces crea una medicina. Pero la actitud hacia la enfermedad y los métodos de luchar contra ella varían enormemente en las distintas tribus primitivas ${ } \gg$ (Ackerknecht 1985: 20).

\footnotetext{
${ }^{6}$ Sobra decir que la expresión «tribus primitivas» responde a una concepción de la época de investigación del autor y que requiere ser interpretada como culturas no literarias (idea que tampoco comparto), etnias, pueblos o culturas en plural.
} 


\section{La magia del hombre medicina}

No me gustaría dejar de considerar el aspecto que podría parecer más sorprendente de los tratamientos de los hueseros Escobar, debido al método eminentemente mecánico y práctico de sus terapias. Me refiero a la incursión, casi de forma inapreciable, del elemento mágico en la terapia de estos rehabilitadores de huesos. Hablo de esa propiedad inductora que Levi-Strauss (1987) designaba como «eficacia simbólica» y que la medicina convencional denomina «efecto placebo». Que, dicho sea de paso, no son exactamente lo mismo como pasaré a detallar a continuación. No obstante, anticipo los elementos que sistemáticamente he podido comprobar que son aplicados a los enfermos con una vocación curativa, e impregnada de la evocación del ritual mágico: el precio de la consulta, el miedo, el dolor, los parches/ las fajas y los chasquidos de huesos.

La eficacia simbólica (Lévi-Strauss 1987b: 216) es una forma de penetración en el inconsciente del paciente para conseguir la cura, ya sea mediante un efecto biológico orgánico, por un efecto psicológico o por cualquier otro mecanismo que desencadene o contribuya a la sanación. Consiste en un tratamiento de la enfermedad en el que el escenario simbólico se sitúa en primer plano.

«La carga simbólica de tales actos les permite constituir un lenguaje: en realidad, el médico dialoga con su paciente no mediante la palabra, sino mediante operaciones concretas, verdaderos ritos que atraviesan la pantalla de la conciencia sin encontrar obstáculo, para aportar directamente su mensaje al inconsciente» (Lévi-Strauss 1987b: 223).

Es decir, los símbolos, pueden tener y tienen un poder curativo. El ejemplo que Lévi-Strauss propone, simplificando mucho, es una curación de un especialista ritual de los indios cuna de Panamá que debe atender un parto con dificultades de la paciente. Para ello desarrolla un complejo ritual chamánico que consiste en entablar una batalla simulada mediante un canto-narración contra las fuerzas del mal que controlan el alma de la paciente y obstaculizan el alumbramiento. El chamán, apoyado por una serie de espíritus protectores vence a la entidad que entorpecía el proceso y tras un pacto de amistad con ella, el parto tiene lugar sin ninguna dificultad. Ese diálogo entre médico y paciente no requiere de ningún contacto físico entre ambos; la eficacia se produce por el convencimiento del sujeto afectado de la realidad de los acontecimientos que están teniendo lugar y por la visualización, de algún modo metafórica, del propio parto en forma de batalla, desencadenándose la función simbólica de la magia. De hecho, el oficiante tiene que atravesar un recorrido muy similar analógicamente al del feto en el parto en su canto-narración.

Como antropólogos, no debemos juzgar las creencias, sino valorar y analizar desde un punto de vista socio-antropológico el impacto y las consecuencias que desencadenan las prácticas. En el caso de Bolivia, en la pasarela que nos ofrece la medicina popular de enfermedades, como por ejemplo el susto ${ }^{7}$ (aparentemente fuera del territorio

\footnotetext{
${ }^{7}$ «El susto en el altiplano boliviano es una enfermedad en la que, ante una determinada circunstancia, como puede ser una fuerte impresión, un disgusto o un enérgico golpe, el sujeto afectado pierde una de sus entidades anímicas (almas) (Fernández 2004: 279). Sólo mediante su restitución a través de la intervención de un yatiri (cierto tipo de especialista ritual) la persona recupera la salud. La medicina convencional es estéril en el campo de esta patología, porque ésta pertenece al campo de la cultura» (Salvador 2010).
} 
biomédico) generan todo un entramado de curaciones simbólicas con un fenómeno de una riqueza cultural extraordinaria. Ya sea de especialistas rituales, formas de curación, escenarios para los tratamientos, itinerarios terapéuticos, etc. Pero la realidad deja claro que esas curaciones simbólicas no sólo tienen campo abonado en la medicina popular, o la medicina indígena, también están integradas en la medicina alopática ${ }^{8}$.

«Para el antropólogo no es difícil descubrir el carácter mágico que adquieren a menudo en la mente del paciente las vitaminas, los microbios, las cifras complejas, etc. Precisamente ésta es una de las más importantes críticas que debe hacerse: los elementos mágicos de nuestra medicina están de forma abrumadora en la parte del paciente» (Ackerknecht 1985: 23).

Por tanto, la eficacia simbólica requiere de un consenso tácito entre sanador y sanado, un convencimiento del carácter simbólico de la terapia. De hecho, en la selva de los símbolos que el médico rastrea para conseguir un diagnóstico, en ese arte interpretativo de la inferencia clínica, siempre la terapia es consonante con lo deducido y el lenguaje común de médico y paciente es el punto de partida para una comunicación consensuada hacia la solución del problema de salud. El paciente acepta la retórica simbólica del diagnostico y el médico ve previamente esos signos y los interpreta con el ojo entrenado por la práctica y las determinaciones sociales de la percepción» (Taussig 1995).

El caso del efecto placebo es similar al de la eficacia simbólica, pero existe la conciencia de lo inocuo del contenido del tratamiento por parte del médico, independientemente de la mayor o menor esperanza en los efectos del mismo. A mi juicio, la fe en la terapia aplicada (provenga o no de un nivel racional o suprarracional) es lo que diferencia a un verdadero especialista ritual de un impostor. Lo que no quiere decir que sus terapias tengan más o menos éxito. A este respecto es francamente clarificador el texto de Lévi-Strauss (1987a) «El hechicero y su magia», en el que analiza el caso de Quesalid. Este hombre, sin creer en el poder de la magia, ni de los brujos, empieza a interesarse por los tratamientos y curaciones chamánicas para desvelar su vertiente de impostura y falsedad. Poco a poco, y fortuitamente, va siendo iniciado en el arte de la curación y, casualmente, empieza a aplicar los conocimientos adquiridos con brillantez en los pacientes y desarrolla una meteórica carrera de éxitos y reconocimientos crecientes. En el camino pule su técnica compartiendo secretos y trucos con otros chamanes, llegando a humillar y ridiculizar a verdaderas leyendas locales de la curación. En el itinerario, Quesalid va tornando poco a poco su postura radical y maniquea (mago eficaz, brujo impostor) con una gama de grises llena de matices. No podemos saber al final del relato si creía o no en su propio arte terapéutico, pero sus

\footnotetext{
${ }^{8}$ La medicina científica o convencional está implícitamente y explícitamente plagada de la utilización de elementos mágicos, ya sea por la intencionalidad del médico, por la percepción del paciente o por la connivencia de ambos. Por ejemplo, el mero hecho de que un médico explique a un paciente que no tiene ninguna enfermedad, que su aspecto es saludable, que su recuperación es inminente, tiene un efecto benéfico sobre la salud, produce bienestar y una sensación de confianza con un alto valor terapéutico. O, en el caso de cirugía, está comprobado que las tasas de recuperación de los paciente es mucho más alta en las circunstancias en las que el cirujano, el médico, o el anestesista explican cómo va a llevarse a cabo la operación, en qué consiste el proceso y cómo va volver el enfermo a la vida normal, comparado con los intervenidos en los que no hay comunicación previa, cuya recuperación es más larga.
} 
resultados ejercían un efecto benéfico y sus burlas se habían disipado en la propia seriedad y perseverancia práctica.

Placebo o eficacia simbólica, los hueseros aplican estos elementos con una intencionalidad simbólica evidente.

\subsection{El precio de la consulta}

Aldo Escobar luce un vehículo todoterreno en la puerta de la clínica cuyo acceso económico es sólo para élites de alto nivel adquisitivo. Es un símbolo que marca el estatus del huesero, asociado a su prestigio, en una especie de círculo simbólico en el que poder, prestigio, posición social y riqueza perfilan la identidad del propietario de la clínica como persona con éxito profesional. El signo de distinción, claramente visible, es comprendido por cualquier paciente que se dirija a la consulta: «Los hueseros cobran caro». Lo que normalmente va asociado a la idea de calidad y eficacia en el servicio. De hecho, es chocante ver el contraste entre pacientes y hueseros en cuanto a vestimenta y apariencia física. Los hueseros visten de forma urbana, a menudo con gorras de béisbol y ropa moderna, mientras que el perfil del enfermo suele combinar un abanico rural y urbano con predominio indígena. Sin embargo, y a pesar del alto precio en relación al nivel socioeconómico medio de Bolivia, la consulta está siempre atestada de gente, con máxima concentración en jueves y domingo.

En el juicio ancestral aymara y quechua, con un carácter histórico vinculado a la economía de subsistencia e intercambio, cada don se recompensa con un contra-don (Malinowski 1986; Mauss 1979; Sahlins 1983) forjándose el sistema de reciprocidad que es el fluido sobre el que discurren las relaciones sociales. O sea, un buen servicio requiere de una contraprestación con un valor equivalente. Lo gratuito, en esta forma de concebir la atención sanitaria, es visto como algo devaluado, estéril desde el punto de vista de la eficacia simbólica: si no cuesta, no tiene valor, ni resultará atractivo. De ahí se deduce el impacto ideológico del potencial curativo de una consulta cara y viceversa.

«En la lógica aymará, la curación cuesta plata. El ser gratuita devalúa la atención, curación y tratamientos a los ojos de esos usuarios. También en la lógica quechua, como me comentaban el personal e investigadores del Hospital Daniel de Bracamonte (Potosí), los usuarios desconfían y se sienten discriminados si son objetos de atención gratuita dentro del programa de Seguro Básico de Salud (Materno-Infantil)» (Flores 2004: 193).

No obstante, aún siendo conscientes de la calidad del servicio, no siempre la hora del pago está exenta de conflictos. Sólo que aquí la posición del huesero es tajante, convencido de la legitimidad de su tarifa. Veamos una transcripción literal de una discusión típica a la hora de escurrir el precio del servicio:

(Usuaria) - Aldo, ¿cuánto es?

(Aldo Escobar) - 450 Bs. Es un mes de tratamiento.

(Usuaria) - Sí, pero no nos cobra así xx.

(Aldo Escobar) - Entonces deberías ir a xx no más.

(Usuaria) - Ahí estuve, de ahí se había venido pues aquí. Él, 60 pesos nos cobra xx. 
(Aldo Escobar) - Deberías ir no más pues ahí, allá le van frotar así.

(Usuaria) - Yo vengo siempre.

(Aldo Escobar) - No uso aceite de comer, no uso Mentisán (una pomada con esencia de eucalipto), aquí no usamos, aquí arreglamos y para que sane colocamos tabaco y huevo.

(Usuaria) - Ya no puedo pagar esos 450 pues.

(Aldo Escobar) - Ya voy a deshacer y listo (se refiere al emplasto), no tengo ningún problema.

(Usuaria) - No puedo pagarte pues, 60 me ha dicho pues xx.

(Aldo Escobar) - Te lo voy a deshacer no tengo ningún problema.

(Usuaria) - No es de deshacerlo, pues sí que te estoy suplicando, ¿cómo me vas a cobrar tanto?

(Aldo Escobar) - Así son los precios aquí, nosotros no frotamos así, yo no meto aceite de comer, ni Mentisán...

(Usuaria) - Hasta 100 te voy a pagar porque xx me ha dicho $60 \ldots$

(Aldo Escobar) - No, mejor se lo deshago doña.

(Usuaria) - ¿Para qué vas a deshacer, pues?

(Aldo Escobar) - Lo voy a deshacer.

(Usuaria) - Tú eres un pariente, no puedes cobrarme así, no puedes hacer esto.

(Aldo Escobar) - Tan poco puedes poner precio del trabajo mío.

(Usuaria) - Él se ha equivocado en no preguntar, es que ¡No! ...

(Aldo Escobar) - No me grite.

(Usuaria) - No te estoy gritando papito, yo te dicho por eso ande, él...

(Aldo Escobar) - Yo voy a deshacer a mí no me interesa, sea quien sea.

(Usuaria) - ¿Cómo puedes deshacer pues?

(Aldo Escobar) - He arreglado los huesos, he arreglado la fractura que tiene, o si no me cree, lo hago sacar radiografía. Está bien. Ya voy hacer sacar si es así... Son siempre Igual. ¡Hasta cuándo!

(Usuaria)... i400!

(Aldo Escobar) - Es fractura de radio, no es luxadura.

(Usuaria) Pero le voy a hacer sacar radiografía entonces.

(Aldo Escobar) - De acuerdo 400, tenemos para sacar radiografía también, yo no engaño como xx, por esa razón ahí tienen todos los días la misma cara durante meses, ahí. Y aquí, vienen a reclamar diciendo: «xx no me ha curado». Yo los boto de aquí cuando vienen de ahí... pero está bien, ¡400! ¿A quién le toca?» (Aldo Escobar, Cliza, Cochabamba, 2009).

Las palabras hablan por sí mismas; es un simple regateo en el que Aldo es prácticamente inflexible, pero justificando con argumentos la calidad de su trabajo. Incluso cuando la persona en cuestión se marcha me comenta que si baja el precio, ni valorarían su trabajo, «ni tendrían ninguna fe en mí».

\subsection{El miedo}

La amenaza y el miedo son usados como instrumentos para concienciar al paciente de la importancia de seguir el tratamiento. Son herramientas con las que los hueseros imponen un sistema de curación y una forma de convencer a sus usuarios de que si respetan las instrucciones prescritas, la curación tendrá un mayor efecto. Por supuesto, 
también es parte de una estrategia urdida para justificar el posible fracaso ante una cura y trasladar al enfermo la responsabilidad por saltarse alguna regla. Aunque estoy convencido de que, a parte del fin instrumental, la imposición verbal de la amenaza tiene un vigoroso valor performativo en el lenguaje de la terapia. Cuando Farith dice: «Si sigues mis recomendaciones (tales como no quitarse la venda, no rascarse en la zona de aplicación del tabaco (!), reposar, volver a las revisiones, etc.) te curarás», está aplicando la misma técnica de reconstrucción de la realidad que los chamanes. Con su emisión performativa «quedaras sanado», a través del espacio simbólico del lenguaje, el médico programa o predispone al enfermo para la curación.

«No olvidemos que, al fin y al cabo, la noción de performatividad proviene de un término acuñado por el filósofo del lenguaje J. L. Austin para referirse a la capacidad que tienen (no de forma exclusiva) ciertas emisiones lingüísticas (llamas preformativas) de constituir, instituir o producir aquello que «nombran», como ocurre con el clásico ejemplo de «Les declaro marido y mujer» emitido por la persona apropiada y en las circunstancias adecuadas. Por ello puede decirse que, en cierto sentido, lo performativo es el dominio donde el poder actúa como discurso, basándose en la reiteración o «cita» de la convención» (García Selgas 2006: 30).

Pongo un ejemplo de juego entre la amenaza y la broma de D. Aldo y un paciente joven que se ha rascado frecuentemente el brazo y es reprendido por saltarse las normas. La carga performativa culmina con un «te curarás» previo a la pequeña burla para descargar la tensión.

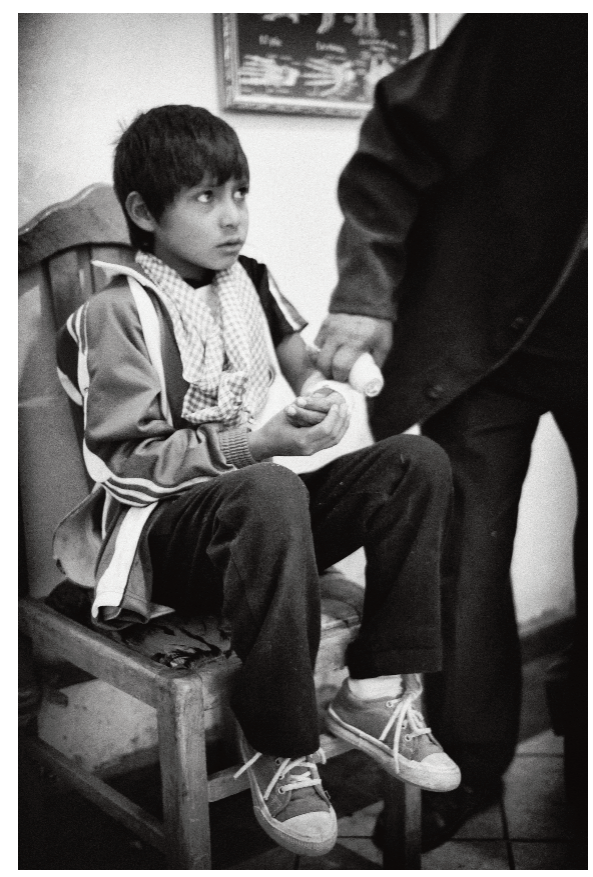


«A ver, ¿has doblado, has hecho ejercicios? ¿No, por qué, a ver por qué no has hecho? [...] No tienes que rascar, no hay que rascar, ya no va ser culpa mía si te haces mover, [...] si te haces de eso, no sé compañero va a ser culpa tuya, ya no de mí, ahí está rectito. [...] No te vas a rascar ya, a veces cuando hay escozor están rascando y eso es peligroso [...] Está tan lindo, tan rectito, está bien no mucho es, ¡te curarás! [...] No sé pues qué habrás hecho, habrás abrazado a alguna chica, ja, ja.»

\subsection{El dolor}

El uso controlado del dolor en la consulta es parte de la ritualización de la terapia de los hueseros impregnada de un elemento simbólico: el dolor como experiencia necesaria para la curación. Su instrumentalización es especialmente manejada en la colocación de huesos, unión de fisuras y fracturas, reposicionamiento de tendones y en otras manipulaciones. La utilización de anestésicos es puramente residual, minimizando el uso de cualquier tipo de calmantes durante las intervenciones. Sólo tras la consulta se administran recetas para analgésicos, antiinflamatorios y preparados con abundancia de calcio para facilitar el fortalecimiento y recuperación de los huesos.

Farith Escobar me comenta que una pequeña dosis de dolor es necesaria para que se produzca el convencimiento del paciente en la eficacia de la cura, explicándome que en las comunidades rurales la convivencia con el dolor es habitual, y que en la tradición quiropráctica y de los frotadores la cura ha de ser con dolor, «como siempre ha sido». Si no hay dolor ahora, piensan (según Farith) que éste, como en la medicina convencional, aparecerá más tarde y no habrá sido todo nada más que una solución aparente.

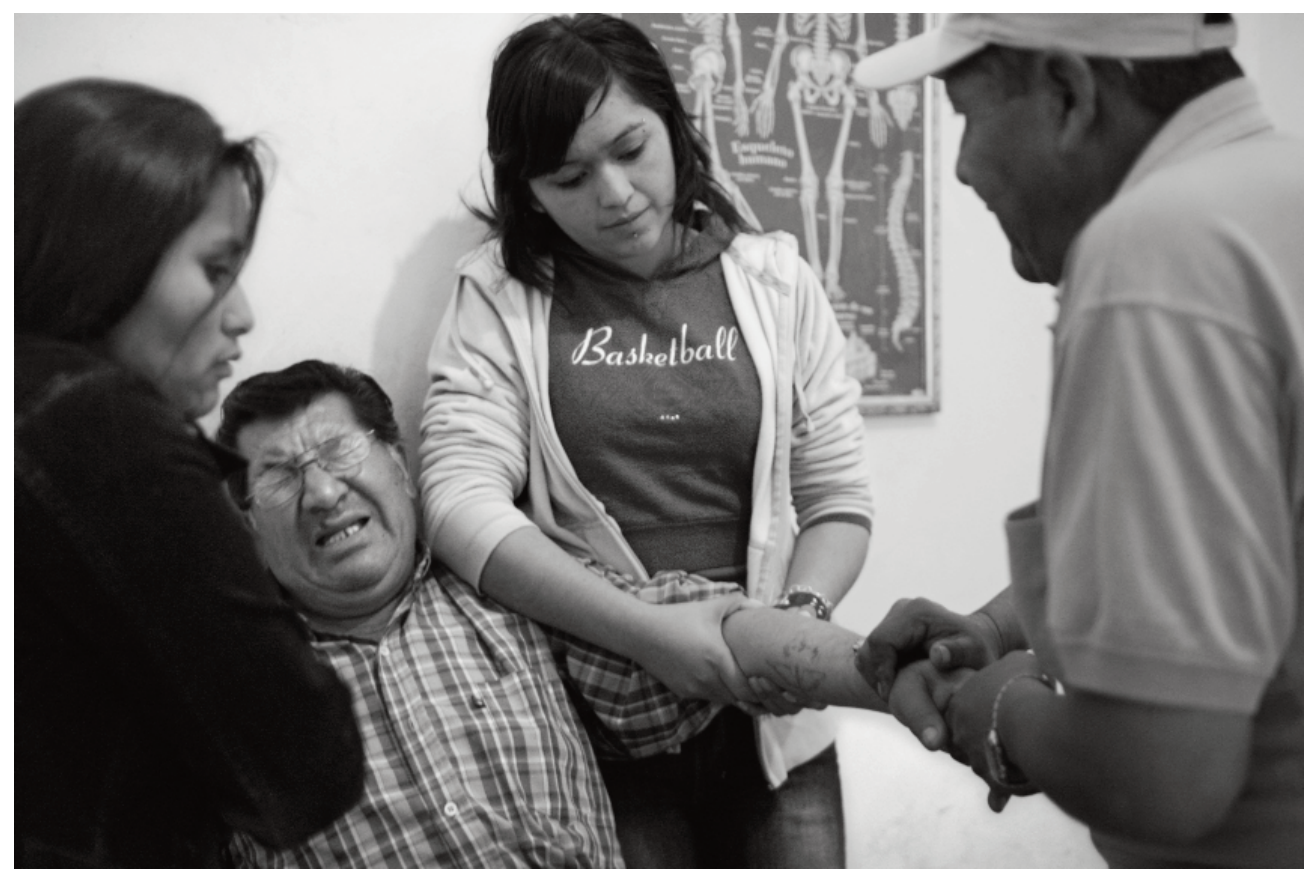


Callahan (2006), en su experiencia de investigación en el hospital kallawaya «Shoquena Husi» de Curva, confirma la visión de los hueseros respecto al dolor y la percepción de eficacia de los tratamientos. Explica cómo comparativamente la medicina científica es concebida como la raíz del problema en la convivencia intercultural de sistemas terapéuticos, precisamente por su lógica paliativa y su huida de la convivencia mínima con el dolor. Por ello, esa actitud de los pacientes, resistentes a todo lo que huela a medicina occidental:

«Para algunas personas la medicina occidental en sí misma es el problema. La lógica cultural local generalmente percibe la medicina convencional como «tabletas» que sirven para calmar dolores en el corto plazo, pero que no curan el problema real y con el tiempo causan daño corporal. La gente que comparte esta percepción de la medicina occidental generalmente va al hospital en casos de accidentes físicos graves o cuando sus enfermedades u otras complicaciones (como en el caso de la joven embarazada) primeramente no responden a los tratamientos de los médicos tradicionales. Esta conclusión está probada por los expedientes del hospital que demuestran que los accidentes y las enfermedades avanzadas, tales como diarrea aguda, están entre las razones más comunes por las que la gente asiste al hospital» (Callahan 2006: 296).

Sabemos que ya durante la primera convivencia de ambas medicinas, a lo largo del antiguo régimen colonial, las farmacias del viejo continente se nutrieron de la medicina autóctona del actual territorio boliviano con excelentes tratamientos y remedios para el dolor (Zallés y De Lucca 1992). Pero la realidad de las comunidades indígenas andinas muestra una consistente y cruda convivencia con el dolor por las circunstancias socioculturales del contexto andino, donde el acceso a calmantes está condicionado, en numerosas ocasiones, por el conocimiento de paliativos naturales para el dolor del especialista en medicina tradicional y por la precariedad de las postas rurales.

En todo caso, conscientes de esa concepción nativa del dolor como elemento necesario para la sanación, los Escobar aprovechan cierto umbral subjetivo de dolor como seña de identidad de sus curaciones y como elemento que persigue, también, la eficacia simbólica de sus tratamientos. Así lo especifican implícitamente cuando hablan de su técnica de curación:

«deseamos también dejar claramente establecido que, solamente en contados casos muy excepcionales y de alto riesgo, utilizamos la anestesia local. - Aldo Escobar [...] Para los dolores consideramos que son suficientes los mates y algunas pócimas que forman parte del $<<$ vademécum $>>$ criollo y popular de la medicina Tradicional - Ramiro Escobar» (Guillén 1995: 8, 51).

\subsection{Parches y fajas}

Un parche es una especie de emplasto adhesivo de venta en farmacias que suele tener un pequeño efecto analgésico y/o antiinflamatorio, dependiendo del tipo de ungüento asociado al mismo. Los hueseros los colocan sistemáticamente en la zona dolorida para conseguir un resultado benéfico y calmante al final de sus manipulaciones. Una faja es una cinta ancha de tela que normalmente es utilizada como vendaje alre- 


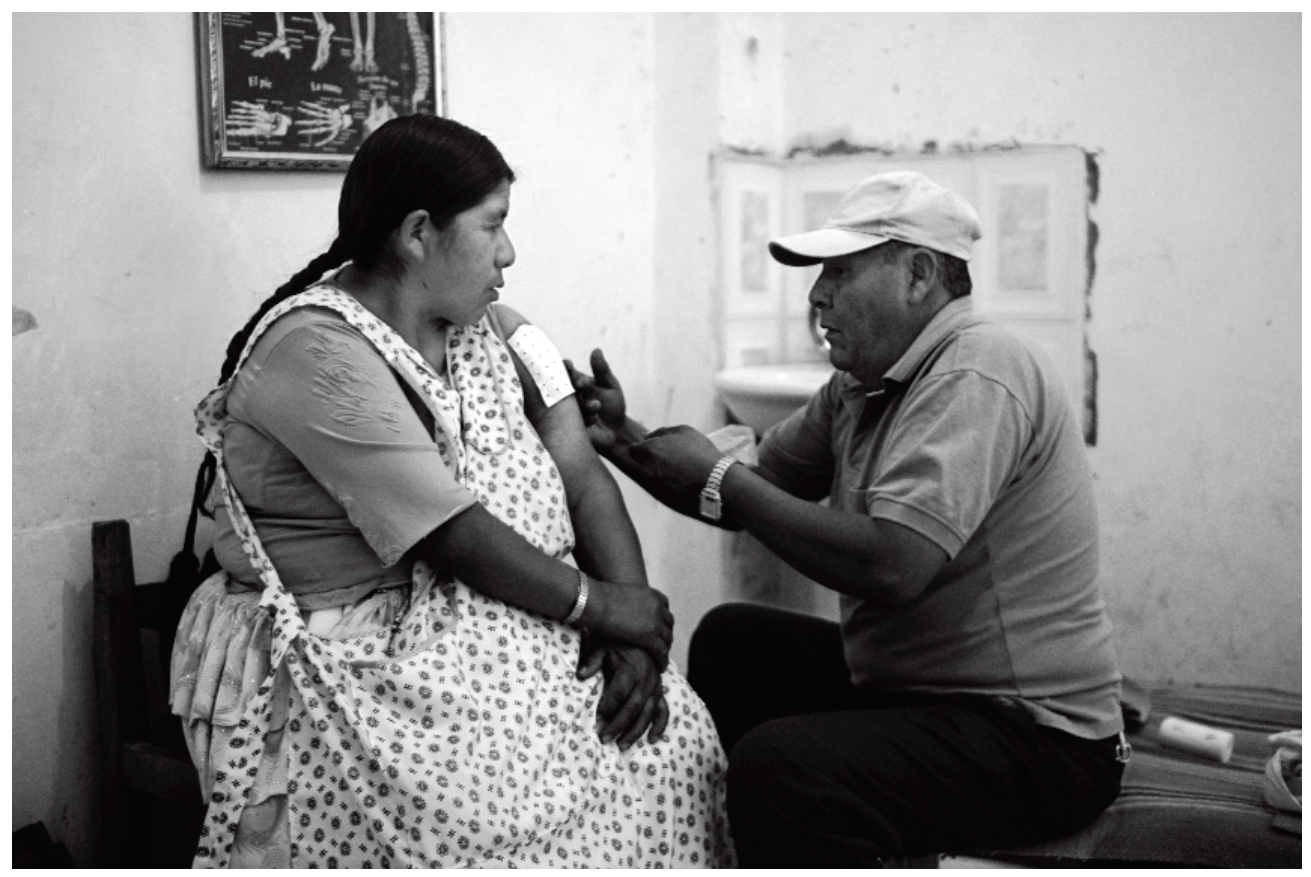

dedor de la cintura u otro lugar del tronco del paciente, también usada como medida de inmovilización del área intervenida.

Uno de los hueseros con quien tuve la oportunidad de conversar sobre el poder terapéutico de estos elementos me confesó que en muchas ocasiones los utilizan como efecto placebo, para que el paciente se vaya tranquilo:

«si no les pones el parchecito o la faja, se creen que no se van a curar. Nos dicen ¿doctor, no me pone un parchecito? Y yo sé que no es necesario, pero así se van más calmaditos. [...] Les pongo parchecito a todos y así me recuerdan durante varios días, ja, ja. [...] Sí o sí se convencen cuando la faja está bien ceñida, [...] traen la faja de casa, bien lejos, sucias o hechas de saco a veces, para irse con ella puesta, bien ceñida» (Huesero Escobar, Cliza, Cochabamba, 2009).

El uso del parche y la faja como elementos preñados de efecto placebo es la única declaración expresa y consciente por parte de un huesero a lo largo de mis estancias. $\mathrm{Su}$ aplicación persigue un fin de adaptación cultural. El ojo del enfermo se ha acostumbrado a asociar el parche o la faja con la curación: en una relación lógica de causaefecto, si no hay parchecito, no hay cura. La familia Escobar (en este caso concreto) está tomando en consideración toda la dimensión de la persona y no sólo la parte dañada (Albó 2004). Si el enfermo no cree en la sanación que no va ligada a la utilización de una pieza de tela (siendo una percepción cultural, pero real para el paciente) no se curará fácilmente. Los seres humanos somos animales simbólicos que transcendemos la dimensión biológica, no somos sólo sacos de moléculas, necesitamos nuestros hechizos. Y de algún modo, tras cada experiencia de aflicción existe un elemento simbólico asociado que no quedará satisfecho hasta el momento en el que como pacientes 
lo dotemos de sentido, aunque sea con un parchecito o un viejo saco reciclado haciendo la función de faja.

\subsection{Chasquidos y crujidos}

Los chasquidos o «crujidos de los huesos» son unos sonidos que se producen al manipular las articulaciones de forma brusca y seca. Es un fenómeno conocido en medicina como «cavitación», o liberación en forma de burbujas de los gases que contiene la cápsula sinovial junto al líquido sinovial. La cápsula al aumentar el volumen por el efecto de la presión ejercida por una manipulación, provoca que dichos gases salgan del líquido lubricante, generando el típico sonido similar al crujir de la madera.

Considero que, en determinadas ocasiones, los hueseros fuerzan los crujidos con el objeto de escenificar mediante ese símbolo sonoro la buena «colocación» de un hueso, de unos tendones o la recuperación de un músculo, cuando, a mi juicio, la manipulación ya ha sido realizada con éxito. Es decir, es lógico que determinadas maniobras en huesos y articulaciones impliquen el chasquido o la cavitación, pero en otras ocasiones el huesero está interviniendo sobre tejido blando, músculos, tendones, fascias9, etc. Sin embargo, he podido observar cómo el propio paciente casi exigía el crujido inquiriendo al huesero: «todavía no ha crujido», lo que generaba un chasquido en cuestión de segundos en las hábiles manos del manipulador. En otras ocasiones, el estímulo verbal procedía del huesero como signo de éxito de la maniobra con un «iya crujió!», seguido de «iparchecito!». Tras su cuidadosa colocación, el componedor despedía amablemente a la persona y enseguida preguntaba «¿a quién le toca?»

Como explica Taussing (1995) salud y enfermedad son parte de la condición humana, y su expresión visible, su manifestación, está marcada por las propias características de la organización social.

«El cuidado de la salud depende, para lograr resultados positivos, de una relación mutua entre el enfermo y la persona encargada de curarlo. En tanto y en cuanto se pueda proveer la salud, son tanto el paciente como el médico quienes la están proveyendo» (Taussig 1995: 134).

En ese espacio negociado entre paciente y médico es donde se pacta el fenómeno de la curación, donde la sanción moral del grupo social dictamina la eficacia de un tratamiento. Poco importa que el contendor físico y químico que somos pueda manipularse mecánicamente para recuperar una lesión, como en el caso de los hueseros. Si la cultura concreta requiere de una dimensión mágica o de un elemento cargado de significado como un símbolo para la curación, será necesario el uso ritualizado de ese símbolo (chasquidos, parchecitos, dolor, miedo, etc.) en las prácticas para recuperar el bienestar físico, psíquico y espiritual de la persona. De lo contrario, probablemente el tratamiento será meramente superficial y se estará ignorando que el significado pro-

\footnotetext{
${ }^{9}$ La fascia es la envoltura de tejido conjuntivo que realiza un número importante de funciones, incluyendo la cobertura y el aislamiento de uno o más músculos. Por extensión, se aplica a cualquier envoltura estructural y que proporciona ayuda y protección estructural.
} 
cede del contexto cultural, el líquido amniótico en el que se sumerge el sentido de la salud y la enfermedad.

\section{Conclusiones}

Plenamente consciente de la necesidad de seguir profundizando en la sugerente investigación de los hueseros de Cliza, me gustaría ofrecer una serie de conclusiones con una clara intención sintética.

La familia Escobar se dibuja como una institución en la medicina popular de la región de Cochabamba, con una tradición y un reconocimiento social sin parangón en el campo de la osteopatía y la medicina natural. Su eficacia médica está avalada por pacientes y especialistas médicos de la medicina convencional y la medicina tradicional, siendo una prueba patente la continuidad en el tiempo y la abundancia de usuarios de sus servicios que se extiende desde finales del S. XIX (con la referencia fundacional documentada de Manuel Escobar) hasta la actualidad. Es lógico pensar que su éxito terapéutico pueda ser proporcional a su prestigio médico, forjado por el boca a boca de pacientes sanados en un periodo de tiempo lo suficientemente largo como para evidenciar o no su calidad profesional.

Los hueseros se nutren de los conocimientos adquiridos por una tradición familiar que abarca (en 2010) a cinco generaciones de jhagodores, incorporando la medicina oficial en la última generación en activo. Los hueseros más jóvenes han compatibilizado su itinerario educativo entre la medicina natural con la práctica-aprendizaje en la consulta familiar, y una incursión (más o menos extensa dependiendo de cada huesero) en la facultad de medicina. En cualquier caso, la hibridación médica de ambas medicinas es un hecho que está transformando las prácticas médicas de los Escobar en un verdadero ejemplo de medicina intercultural que combina los elementos más eficientes de la tradición y de la modernidad, respetando los principios y creencias de los usuarios de los servicios. Su adaptación, lejos de reificar a una medicina sobre otra, estimula el diálogo entre sistemas médicos, en consonancia con las recomendaciones de la Organización Mundial de la Salud que aboga por el respeto y la integración de todos los conocimientos médicos de cada territorio, incorporando a la medicina alopática la medicina tradicional.

Hay dos elementos característicos del tratamiento de la familia Escobar que son un sello identitario propio: el emplasto de yema de huevo y tabaco, y la maniobra Escobar. Requeriría una investigación ad hoc verificar la procedencia endógena o exógena de ambos recursos, pero la comunidad de naturistas entrevistados en Cochabamba atribuyen a la tradición Escobar, al menos, la maniobra para la llamada subluxación sacroilíaca, la que he denominado «maniobra Escobar» que es utilizada en el tratamiento y la curación de las hernias discales. Su aplicación es una suerte de cirugía invisible que permite la recuperación, en muchos casos, sin tener que abrir el cuerpo. Como ya he explicado, en torno a la mitad de los pacientes visitan a los hueseros por lumbalgias que son tratadas con la citada maniobra. También se asocia de forma constante el uso del tabaco y la yema de huevo a los hueseros. Aunque su autoría es más incierta, de lo que no cabe duda es de que la mejora y perfeccionamiento de la posible 
receta original, así como la aplicacióndel emplasto mediante una fórmula más sofisticada, quizás con algún ingrediente no revelado por la familia, y la mayor eficacia obtenida mediante su combinación con las férulas de cartón hechas expresamente para las necesidades de cada paciente.

Por último, en un terreno tan mecánico y aparentemente «objetivo» como la osteopatía natural, los hueseros (de forma consciente o inconsciente, dependiendo del recurso) hacen uso del «efecto placebo» o de la «eficacia simbólica» a través del precio de la consulta, el miedo, el dolor, los parchecitos y las fajas y los crujidos de huesos como hemos visto en el apartado dedicado a la magia del hombre-medicina. La utilización del rito simbólico como soporte de la curación es consonante con el sistema de creencias de los pacientes de la familia Escobar. Responde a una adaptación pragmática a una cosmología enraizada en la tradición andina. Estos elementos simbólico-mágicos son aplicados terapéuticamente en función del perfil ideológico del paciente y del criterio del huesero que se basa en su experiencia e intuición para su uso. Lo relevante de este fenómeno es la incorporación a la práctica médica de lo simbólico para la mejora de la salud del usuario de los servicios, con una vocación que persigue la mejora en la calidad de vida del afectado.

La cirugía invisible se materializa en el uso de una estrategia híbrida que combina, por un lado, elementos de las múltiples esferas que componen al animal simbólico (lo ideológico, emocional, espiritual, lo físico, biológico, cultural, social, etc.), y por, otro la integración de la experiencia de varios sistemas médicos (medicina occidental, indígena, osteopatía, medicina natural, etc.) El resultado de la terapia de los hueseros Escobar de Cliza es único, y probablemente sea un modelo para aprender acerca de la integración de saberes médicos, un rico mosaico de diálogo «inter» e «intra» cultural vivo, dinámico y que demuestra ser eficaz para un contexto sociocultural determinado.

\section{Referencias bibliográficas}

ACKERKNECHT, Erwin

1985 Medicina y antropología Social. Madrid: Akal.

Albó, Xavier

2004 «Interculturalidad y salud», en Salud e Interculturalidad en América Latina. Perspectivas antropológicas, Gerardo Fernández Juárez, coord., pp. 65-74. Quito: Abya Yala.

Baer, Roberta D., Susan C. Weller, Juan Carlos GonzÁlez Faraco y Josefa Feria Martín 2006 «Las enfermedades populares en la cultura española actual: un estudio comparado sobre el mal de ojo». Revista de Dialectología y Tradiciones Populares 61 (1): 139156.

BORDA, Jacqueline (coord.)

1953 Seminario taller de medicina tradicional. Cochabamba: Universidad Mayor de San Simón. 
Callahan, Mollie

2006 «El hospital kallawaya 'Shoquena Husi' de Curva. Un Experimento en Salud Intercultural», en Salud e interculturalidad en América Latina. Antropología de la salud y crítica intercultural, Gerardo Fernández Juárez, coord., pp. 289-304. Quito: Abya Yala.

DíAZ MADERUElo, Rafael

1983 «Sobre el valor simbólico de la enfermedad en el Nordeste brasileño». Revista Española de Antropología Americana 13: 197-206.

FERNÁNDEZ JuÁREZ, Gerardo

1998 «Enfermedad, moda y cuerpo social en el altiplano aymara: Un ‘boceto’ de inspiración colonial sobre modelos de identidad en los Andes». Revista Española de Antropología Americana 28: 259-281.

2004 «'Ajayu, animu, kuraji'. La enfermedad del ‘susto’ en el altiplano de Bolivia», en Salud e Interculturalidad en América Latina. Perspectivas antropológicas, Gerardo Fernández Juárez, coord., pp. 279-304. Quito: Abya Yala.

2009 «Sin abrir el cuerpo. Cirugías amerindias», en Salud e Interculturalidad en América Latina. Prácticas quirúrgicas y pueblos originarios, Gerardo Fernández Juárez, coord., pp. 7-21. Quito: Abya Yala.

FERRÁndiz Martín, Francisco

2004 Escenarios del cuerpo. Espiritismo y sociedad en Venezuela. Bilbao: Universidad de Deusto.

Flores Martos, Juan Antonio

2004 «Una etnografía del 'año de provincias' y de ‘cuando no hay doctor'. Perspectivas de salud intercultural en Bolivia desde la biomedicina convencional», en Salud e Interculturalidad en América Latina. Perspectivas antropológicas, Gerardo Fernández Juárez, coord., pp. 181-212. Quito: Abya Yala.

Foster, George M.

1980 «Relaciones entre la medicina popular española y latinoamericana», en La antropología médica en España, Michael Kenny y Jesús de Miguel, coords., pp. 123147. Barcelona: Anagrama.

García Selgas, Fernando J.

2006 «Apuntes sobre la interdependencia entre sentido y corporalidad», en Cuerpo y Medicina. Textos y contextos culturales, Beatriz Muñoz González y Julián López García, coords., pp. 23-35. Cáceres: Cicón Ediciones.

GUILLÉN G., Guido

1995 Centro de rehabilitación de huesos Jhaghodores «Escobar». Medicina alternativa nativa. Cochabamba.

LÉVI-STRAUSS, Claude

1987a «El hechicero y su magia», en Antropología Estructural, pp. 195-210. Barcelona: Paidós.

1987 «La eficacia simbólica», en Antropología Estructural, pp. 211-227. Barcelona: Paidós.

MALINOWSKI, Bronislaw

1986 Los Argonautas del Pacífico occidental. Barcelona: Península. 
MAUss, Marcel

1979 «Ensayo sobre los dones, motivo y forma del cambio en las sociedades primitivas», en Sociología y antropología, pp. 155-263. Madrid: Tecnos.

MuÑoz GonZÁLEz, Beatriz y Julián LóPEz GARCía (coords.)

2006 Cuerpo y Medicina. Textos y contextos culturales. Cáceres: Cicón Ediciones.

PAREDES, Rigoberto

1963 Mitos, supersticiones y supervivencias populares de Bolivia. La Paz: Ediciones Isla.

Perdiguero, Enrique

2006 «Una reflexión sobre el pluralismo médico», en Salud e interculturalidad en América Latina. Antropología de la salud y crítica intercultural, Gerardo Fernández Juárez, coord., pp.33-49. Quito: Abya Yala.

SAHLINS, Marshall

1983 Economía de la edad de piedra. Madrid: Akal.

Salvador Hernández, Pedro Pablo

2010 «Salud e interculturalidad: paradigmas cochabambinos». Comunicación presentada en el I Congreso Internacional en Red de Interculturalidad y Educación.

SEPPILLI, Tulio

2000 «De qué hablamos cuando hablamos de factores culturales en salud. A modo de presentación», en Medicina y cultura. Estudios entre la antropología y la medicina, Enrique Perdiguero y Josep M. Comelles, eds., pp. 33-44. Barcelona: Bellaterra.

TAussig, Michael

1995 «La reificación y la conciencia del paciente», en Un gigante en convulsiones, pp. 110-146. Barcelona: Gedisa.

ZALLÉS, Jaime y Manuel De LuCCA

1992 Flora medicinal boliviana. La Paz: Los Amigos del Libro. 